\title{
Management Index Systems and Energy Efficiency Diagnosis Model for Power Plant: Cases in China
}

\author{
Jing-Min Wang, XiaoJie Ge, LiLi Zhang, and Hang Zhang \\ Department of Economic Management, North China Electric Power University, Baoding 071003, China \\ Correspondence should be addressed to XiaoJie Ge; gexiaojie0809@163.com
}

Received 6 June 2016; Accepted 10 August 2016

Academic Editor: Sébastien Poncet

Copyright (C) 2016 Jing-Min Wang et al. This is an open access article distributed under the Creative Commons Attribution License, which permits unrestricted use, distribution, and reproduction in any medium, provided the original work is properly cited.

In recent years, the energy efficiency of thermal power plant largely contributes to that of the industry. A thorough understanding of influencing factors, as well as the establishment of scientific and comprehensive diagnosis model, plays a key role in the operational efficiency and competitiveness for the thermal power plant. Referring to domestic and abroad researches towards energy efficiency management, based on Cloud model and data envelopment analysis (DEA) model, a qualitative and quantitative index system and a comprehensive diagnostic model (CDM) are construed. To testify rationality and usability of CDM, case studies of largescaled Chinese thermal power plants have been conducted. In this case, CDM excavates such qualitative factors as technology, management, and so forth. The results shows that, compared with conventional model, which only considered production running parameters, the CDM bears better adaption to reality. It can provide entities with efficient instruments for energy efficiency diagnosis.

\section{Introduction}

In China, the amount of coal-fired thermal power takes up about $80 \%$ of the total generating production, and the coal consumption accounts for $50 \%$ of the total production. The Chinese average coal consumption is about $370 \mathrm{~g} / \mathrm{kW} \cdot \mathrm{h}$, surpassing the counterpart of developed countries like Japan and Germany by $55 \mathrm{~g} / \mathrm{kW} \cdot \mathrm{h}$. Therefore, it is imperative for China to manage the factors affecting energy efficiency and establish a scientific energy efficiency diagnosis and analysis mechanism. It is also significant for Chinese power plants to improve the energy efficiency.

The domestic scholars and those abroad have done deep researches in the factors affecting power plants' energy efficiency management. From the perspective of the operation mode of thermal power unit, Wang [1] analyzed the factors influencing energy efficiency. Dan [2] suggested that the influential factors of comprehensive benefit indexes include load rate, coal consumption rate, unit capacity of water consumption, and electricity consumption to grid. Graus and Worrell [3] conducted statistical analysis of electricity sales amount (from 2001 to 2006) suggesting that energy efficiency is affected by the power consumption. The existing researches focus on operational parameters during production process. However, in practice, human factors [4], like transformation techniques [5] and external environment alike [6], could affect the long-term development of power plants. Meanwhile, there are few studies that have been conducted on the impact of management level [7], energy saving reconstruction, and so forth on energy efficiency. Any specific influencing factor indicator system has not been given yet [8].

In the field of the energy efficiency diagnosis model, Hitachi Research Laboratory initially established the flame image recognition system, which improved the efficiency of boiler system via the analysis of the combustion condition [9]. Jun [10] proposed strategies to realize optimal operation by lowering oxygen content in boiler, boiler's flue gas temperature, and air leakage rate of the air preheater.

Aimed at the energy saving diagnosis of generator set, the American Electric Power Research Institute set up a comprehensive economic diagnosis research plan and the expert online property diagnosis system of industrial equipment installation [11]. In the early 1990s, the artificial intelligence and neural network diagnosis system were gradually introduced into power plant. The Intelligent diagnosis has become a tendency worldwide. Intelligence systems, such as 
TABLE 1: Effect of variation of the boiler thermal on efficiency of coal consumption.

\begin{tabular}{|c|c|c|c|c|c|c|}
\hline \multirow{2}{*}{$\begin{array}{l}\text { Sequence number } \\
1\end{array}$} & \multirow{2}{*}{$\begin{array}{c}\text { Influence factor } \\
\text { Oxygen content at furnace outlet }\end{array}$} & \multicolumn{3}{|c|}{ Variation } & \multirow{2}{*}{$\begin{array}{c}\begin{array}{c}\text { Variation of } \\
\text { energy efficiency } \\
(\%)\end{array} \\
0.4\end{array}$} & \multirow{2}{*}{$\begin{array}{c}\begin{array}{c}\text { Variation of coal } \\
\text { consumption } \\
(\mathrm{g} / \mathrm{kW} \cdot \mathrm{h})\end{array} \\
1.2\end{array}$} \\
\hline & & Variation & 1 & $\%$ & & \\
\hline 2 & Carbon content in fly ash & Increase & 1 & $\%$ & -0.15 & 0.5 \\
\hline 3 & Exhaust temperature & Increase & 1 & ${ }^{\circ} \mathrm{C}$ & -0.04 & 0.12 \\
\hline 4 & Air intake temperature & Increase & 1 & ${ }^{\circ} \mathrm{C}$ & 0.04 & 0.12 \\
\hline
\end{tabular}

Data resource: Xi'an Thermal Power Research Institute Co., Ltd.

American online performance monitoring system, Italian PERFEXS expert system, and American SMOP expert system, have been successfully developed and put into practice.

Nevertheless, most of the previous energy efficiency diagnosis only focuses on thermal economic performance and operation parameter analysis during the power production and lacks the study of influential factors (such as management level and energy saving transformation degree) on energy efficiency. There is still space for the research of the energy efficiency indexes diagnosis based on the combination of qualitative and quantitative indexes.

In order to objectively reflect the energy efficiency influential mechanism of thermal plants, this paper presents energy management index system, which includes unit operation, energy saving technology, and management level, as well as the comprehensive energy efficiency diagnosis model based on DEA model. In practice, these results of this paper help power plants to manage energy efficiency.

\section{Construction of Index System for Comprehensive Energy Efficiency Influencing Factors in Thermal Power Plant}

Several compound indexes interactively exert impact on energy efficiency, not by separated single index. Compound indexes not only embody quantitative technical and economic parameters, but also embody qualitative indicators such as power-saving and management measures. Consequently, in the duration of index system establishment, scientific reflection on power plant economic operation is an essential requirement. Apart from this, the specific index system should lay a substantial foundation for the thermal power plant to accelerate technological transformation, tap into the internal potential, and continuously improve the operation and management level.

2.1. Quantitative Index Screening. According to the energy structure of the thermal power plants, the main consumption is coal. In order to facilitate quantification, production departments of the power at home and abroad mainly adopt "the power supply coal consumption rate" or "heat consumption rate" as the primary indicator in the process of judging the efficiency of power plants; both are important factors in the evaluation of energy saving for power plant. In this light, the following quantitative indicators are selected mainly from the perspective of coal consumption of electricity and coal consumption for power supply to show their respective effects on the energy efficiency of power plants.

2.1.1. Boiler Thermal Efficiency. Utility boiler is the main equipment in the combustion system. Boiler thermal efficiency refers to the ratio of the boiler heat output and heat input. It is calculated by measuring heat loss through the indirect analysis of boiler effective use of heat. Its variation affects coal consumption for power generation and coal consumption for power supply. Xian Thermal Power Research Institute Co., Ltd. examined a unit with capacity of $300 \mathrm{MW}$. The experiment results show the influence of variation of the boiler thermal on the efficiency of coal consumption for power generation, as shown in Table 1 .

In addition, the boiler efficiency has an effect on coal consumption for power supply. A study from a power plant in the northeast of China with capacity of $300 \mathrm{MW}$ unit in 2005-2014 operating conditions [12] indicates a negative correlation of the thermal efficiency of the boiler and the coal consumption of power supply. Boiler combustion condition and the well-conditioned heating paragraphs surface of heat exchanger, along with the improvement of the overall thermal efficiency, can ensure reduction of coal consumption for power generation and coal consumption of electricity supply. Based on this, the thermal efficiency of the boiler is the priority of the analysis of energy efficiency.

The baseline of boiler efficiency calculation is based on the amount of fuel consumption per kilogram. Take the fuel received from the net calorific value as the input heat. Boiler thermal efficiency can be generalized as follows:

$$
\eta_{\mathrm{g}}=\frac{\left(100-q_{2}-q_{3}-q_{4}-q_{5}-q_{6}\right)}{100} .
$$

In the equation, $\eta_{\mathrm{g}}$ is boiler thermal efficiency, $\% ; q_{2}$ is waste heat loss, $\mathrm{kJ} / \mathrm{kg} ; q_{3}$ is unburned gas loss, $\mathrm{kJ} / \mathrm{kg} ; q_{4}$ is solid unburned loss, $\mathrm{kJ} / \mathrm{kg} ; q_{5}$ is heat loss, $\mathrm{kJ} / \mathrm{kg}$; and $q_{6}$ is ash physical heat loss, $\mathrm{kJ} / \mathrm{kg}$.

2.1.2. Turbine Thermal Efficiency. Turbine is one of the most influential engines in the electrical system, the operation of which in good condition or not affects the heat loss. The main factors influencing the efficiency of steam turbine consist of noncompliance pressure of condenser, steam parameters deviation, and feed water heating process of heat loss, which exert a direct impact on the overall efficiency of power generation. The thermal efficiency of steam turbine generator 
units is the percentage of total heat consumption per kilowatt hour of steam turbine generator unit. The formulas are as follows:

$$
\begin{gathered}
\eta_{q}=\frac{3600}{q} * 100, \\
q=\frac{Q_{s r}-Q_{g r}}{P_{q j}} .
\end{gathered}
$$

In the equation, $\eta_{q}$ is turbine thermal efficiency, $\%$; $q$ is heat rate, which is the ratio of turbine power consumption and electrical power outlet side, $\mathrm{kJ} /(\mathrm{kW} \cdot \mathrm{h}) ; \mathrm{Q}_{s r}$ is unit heat consumption, which is constituted by main steam, final water supply, steam turbine reheat steam, cold reheat steam, water for the attemperation of reheater, and water for the attemperation of super heater, $\mathrm{kJ} / \mathrm{h} ; Q_{g r}$ is unit for the heat, $\mathrm{kJ} / \mathrm{h}$; and $P_{q j}$ is electrical power outlet side, $\mathrm{kW}$.

2.1.3. Pipeline Efficiency. Pipeline efficiency is the percentage of the heat from the boiler to that from boiler combustion. The efficiency loss mostly embraces pure pipeline losses, sewage unit loss, steam and water loss, and so forth. Underutilized energy of the steam turbine results in a direct impact on the power consumption.

The equation is

$$
\eta_{g d}=\frac{\sum Q_{s r}}{\sum Q_{l}} \times 100 .
$$

In the equation, $\eta_{g d}$ is pipeline efficiency, $\% ; \sum Q_{s r}$ is heat input of turbine in statistical period, $\mathrm{kJ} / \mathrm{h}$; and $\sum Q_{l}$ is heat output of boiler in statistical period, GJ.

2.1.4. Power Consumption Rate. Factory electricity is consumed by the auxiliary equipment of power plant, directly determining how much power supply and power consumption. Plant power consumption rate refers to the proportion of power self-consumption accounting for generating capacity. Its variation is pertinent to the design of auxiliary system equipment and every $1 \%$ change will produce about $3.3 \mathrm{~g} / \mathrm{kW} \cdot \mathrm{h}$ of power supply coal consumption. According to a rough estimate, assuming that price is $\$ 0.06 / \mathrm{kW} \cdot \mathrm{h}$, operating $5000 \mathrm{~h}$, if annual plant electricity rate decreased by $0.1 \%$, equivalent to adding extra 17.25 billion $(\mathrm{kW} \cdot \mathrm{h})$, another $\$ 104$ million output value would be created. Therefore, as one of the important technical and economic indicators to measure the performance of generating units, the power efficiency of the plant plays a decisive role in the analysis of the influence factors of energy efficiency. Hence,

$$
\begin{aligned}
e_{p} & =\frac{E_{p}}{E}, \\
E_{p} & =E_{c}-E_{d} .
\end{aligned}
$$

In the equation, $e_{p}$ is power consumption rate, $\%$; $E_{p}$ is plant for electricity generation in the calculation period, $\mathrm{kW} \cdot \mathrm{h} ; E_{c}$ is total electricity consumption in the calculation period, $\mathrm{kW} \cdot \mathrm{h}$; and $E_{d}$ is nonproduction plant consumption which should be deducted in the calculation period, $\mathrm{kW} \cdot \mathrm{h}$.
2.1.5. Load Rate. Load rate is the ratio of the average load to the maximum load. Load insufficiency will result in the heat loss of the pipe network, corresponding to the efficiency decrease of the boiler and steam turbine. The load rate thus can be used as a key indicator to quantify the variation of the load in the specified time and the effective utilization assessment of the electrical equipment.

The equation is

$$
p=\frac{p_{p j}}{p_{\max }} \times 100 \% .
$$

Unit's average load is the ratio of the generating capacity of turbo generator and run time during statistics, which is

$$
p_{p j}=\frac{W_{f}}{h} .
$$

In the equation, $p_{p j}$ is unit's average load in the statistical period, $\mathrm{kW}$; $p_{\max }$ is unit's maximum load in the statistical period, $\mathrm{kW} ; W_{f}$ is unit's power generation in the statistical period, $\mathrm{kW} \cdot \mathrm{h}$; and $h$ is unit's operating time, $\mathrm{h}$.

Through the above analysis, taking the main power plant operation parameters of thermal power plant in the duration of production into account, quantitative indexes are eventually given as follows: thermal efficiency of the boiler, the thermal efficiency of steam turbine generator unit, pipeline efficiency, plant electricity rate, and load rate.

2.2. Qualitative Indicators Screening. From the analysis above, it can be seen that the production and operation parameters of thermal power enterprises in the process of thermal power generation can better reflect the factors that directly affect the efficiency of the power plant, similar to the hardware of the power generation system. However, hardware lays the foundation of system operation, while the software sustains maintenance and improvement of system operation. Therefore, the software comprising enterprise internal energy saving technology and management also affects energy efficiency of the power plant major. In light of this, according to combination with the major production process and system in the duration of power enterprises production, this paper qualitatively screened and analyzed such quantitative indexes as management characteristics.

For the rationality of the qualitative indicators, the 01 cumulative scoring method to screen the qualitative indicators is applied. In accordance with specific evaluation indicators, pairwise indexes comparison method is utilized to conform relative importance of the objects. "1" indicates relatively more important, otherwise " 0 ", assuming “*” as comparison with their own. The next step is to find out the cumulative score of each program; calculate the weight coefficient of each index; and finally order the importance of the indexes.

2.2.1. Determination of the Qualitative Indicators to $\mathrm{Be}$ Screened. Referring to "the thermal power industry, cleaner production evaluation index system" issued by the National Development and Reform Commission (Implementation) and other documents, along with discussion with 10 experts 
TABLE 2: The results of the evaluation of an expert on the 0-1 score matrix table.

\begin{tabular}{|c|c|c|c|c|c|c|c|c|c|c|}
\hline Index & $G_{1}$ & $G_{2}$ & $G_{3}$ & $G_{4}$ & $G_{5}$ & $G_{6}$ & $G_{7}$ & $G_{8}$ & $G_{9}$ & Accumulative score $q_{i k}$ \\
\hline$G_{1}$ & $*$ & 0 & 1 & 1 & 1 & 1 & 0 & 1 & 1 & 6 \\
\hline$G_{2}$ & 1 & * & 1 & 0 & 1 & 1 & 0 & 1 & 0 & 5 \\
\hline$G_{3}$ & 0 & 0 & $*$ & 0 & 1 & 0 & 0 & 1 & 0 & 2 \\
\hline$G_{4}$ & 0 & 1 & 1 & $*$ & 1 & 1 & 0 & 1 & 1 & 6 \\
\hline$G_{5}$ & 0 & 0 & 0 & 0 & $*$ & 0 & 0 & 1 & 0 & 1 \\
\hline$G_{6}$ & 0 & 0 & 1 & 0 & 1 & $*$ & 0 & 1 & 1 & 4 \\
\hline$G_{7}$ & 1 & 1 & 1 & 1 & 1 & 1 & $*$ & 1 & 1 & 8 \\
\hline$G_{8}$ & 0 & 0 & 0 & 0 & 0 & 0 & 0 & $*$ & 0 & 0 \\
\hline$G_{9}$ & 0 & 1 & 1 & 0 & 1 & 0 & 0 & 1 & $*$ & 4 \\
\hline Total & & & & & & & & & & $Q=36$ \\
\hline
\end{tabular}

TABLE 3: Comprehensive evaluation matrix table.

\begin{tabular}{|c|c|c|c|c|c|c|c|c|c|c|c|c|}
\hline Index & $G_{1}$ & $G_{2}$ & $G_{3}$ & $G_{4}$ & $G_{5}$ & $G_{6}$ & $G_{7}$ & $G_{8}$ & $G_{9}$ & $\begin{array}{c}\text { Total cumulative } \\
\text { score } q_{i}\end{array}$ & $\begin{array}{l}\text { Importance } \\
\text { coefficient } \mu_{i}\end{array}$ & $\begin{array}{c}\text { Importance } \\
\text { ranking }\end{array}$ \\
\hline$\overline{G_{1}}$ & $*$ & & & & & & & & & 72 & $72 / 360$ & 1 \\
\hline$G_{2}$ & & * & & & & & & & & 64 & $64 / 360$ & 2 \\
\hline$G_{3}$ & & & $*$ & & & & & & & 20 & $20 / 360$ & 7 \\
\hline$G_{4}$ & & & & $*$ & & & & & & 48 & $48 / 360$ & 4 \\
\hline$G_{5}$ & & & & & $*$ & & & & & 13 & $13 / 360$ & 9 \\
\hline$G_{6}$ & & & & & & $*$ & & & & 37 & $37 / 360$ & 5 \\
\hline$G_{7}$ & & & & & & & * & & & 58 & $58 / 360$ & 3 \\
\hline$G_{8}$ & & & & & & & & * & & 14 & $14 / 360$ & 8 \\
\hline$G_{9}$ & & & & & & & & & $*$ & 34 & $34 / 360$ & 6 \\
\hline Total & & & & & & & & & & 360 & 1.00 & \\
\hline
\end{tabular}

in three large-scale power generation enterprises, this paper selected the following nine qualitative indexes to be screened:

$G_{1}$ : advanced degree of operating equipment

$G_{2}$ : operation optimization of circulating water system

$G_{3}$ : the degree of preventive maintenance process

$G_{4}$ : water reuse

$G_{5}$ : pollutant emissions

$G_{6}$ : coal management system

$G_{7}$ : unit operation management system

$G_{8}$ : the establishment of clean production management system

$G_{9}$ : energy conservation policy implementation

2.2.2. Experts Scoring Qualitative Indicators. 10 experts, according to three distinct power enterprise production operation and management situations, rate the nine qualitative indicators on a scale of 1 to 10 by means of back-toback approach. Accumulative score $\left(q_{i k}\right)$ of each qualitative indicator represents the relative importance of each expert on the recognition of the relative importance of different programs. Q stands for total score of score sheets; calculation of $Q$ can be described as follows:

$$
Q=\frac{n(n-1)}{2}=\sum_{i=1}^{n} q_{i k}, \quad k=1,2, \ldots, p .
$$

Table 2 shows the score of $K$ expert for the $i$ th index; $N$ is the number of indicators.

2.2.3. Summarize the 0-1 Score Table and Then Rank the Importance of Each Index. 0-1 matrix table will be gathered together into the 0-1 comprehensive evaluation matrix table (Table 3); then calculate the total cumulative score. Next, order the importance of the factor. Among them, the total cumulative score and the importance coefficient were calculated by the following formula:

Total cumulative score: $q_{i}=\sum_{k=1}^{p} q_{i k}$

Importance coefficient: $\mu_{i}=\frac{q_{i}}{\sum_{i} q_{i}}=\frac{\sum_{k} q_{i k}}{\sum_{i} \sum_{k} q_{i k}}$.

Based on the above calculation formula, the importance order of $G_{1}-G_{9}$ is finally obtained.

According to 0-1 cumulative score, the final selected qualitative indicators are as follows: operation equipment 
TABLE 4: Influence factors index system of energy efficiency management in thermal power plant.

\begin{tabular}{ll}
\hline First-grade indexes & Second-grade indexes \\
\hline \multirow{2}{*}{$\begin{array}{l}\text { Operating } \\
\text { parameters of power }\end{array}$} & $\begin{array}{l}\text { Thermaler thermal efficiency } \\
\text { plant }\end{array}$ \\
& $\begin{array}{l}\text { Pipeline efficiency of steam turbine } \\
\text { Plant power consumption rate }\end{array}$ \\
& Load rate \\
\hline Energy saving & Advanced degree of operating equipment \\
reconstruction & Operation optimization of circulating \\
technology & water system \\
& Reclaimed water reuse \\
\hline Comprehensive & Admission coal management system \\
management level & Unit operation management level \\
& Energy saving policy implementation \\
\hline
\end{tabular}

advanced degree, circulating water system operation optimization degree, reclaimed water degree, admission coal management system, unit operation and management system, and energy saving policy implementation efforts.

The principals of index extraction lie in the combination of comprehensiveness and emphasis, coconstraints between influence and controllability, integration of qualitative and quantitative technique, and coalition of simplicity with complexity. Referring to major processes and management characteristics, factors affecting energy efficiency of the power plant are analyzed from the perspective of plant operation parameters, energy saving technology, and comprehensive management level. The model could compensate the defect of conventional index system which only focuses on the technical and economic indexes, ignoring qualitative indicators, and finally determines the final diagnosis of energy efficiency influence factors index system, just as displayed in Table 4 .

\section{Comprehensive Energy Efficiency Diagnosis Model Based on One-Dimensional Cloud Model and DEA Model}

3.1. Based on Qualitative Indicators. In the 1990s, Deyi et al. constructed Cloud model [13-16] to address the defect of the probability theory and fuzzy mathematics when dealing with uncertain indicators, proposing an uncertain conversion model with qualitative concept and quantitative description. The process of computing is given by the cloudization of random variables via its digital feature, so as to realize the conversion from fuzzy concept to specific data, the results of which are displayed in the form of graphic, featuring more intuitive and specific than conventional technique.

Suppose that $U$ is a quantitative domain expressed by precise numerical, $X \subseteq U$. T stands for a fuzzy set, part of fuzzy space $U$. For any element $x(x \in X)$, there always exists a random number with $C_{T}(x) \in[0,1]$, a stable tendency, namely, subordinate degree $x$ to $T$. Concept $T$ mapping from domain $U$ to range of distribution in data space $[0,1]$

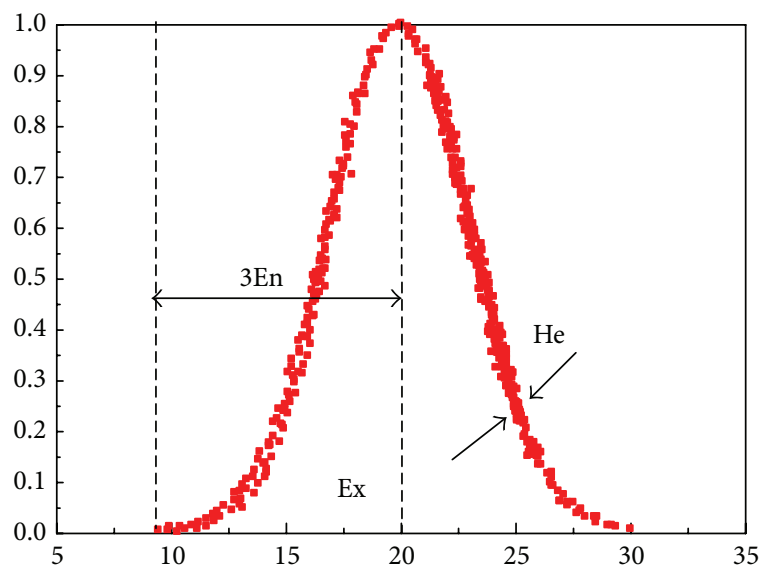

FIgURE 1: Digital characteristics of the Cloud.

is named as membership Cloud, simplified as the Cloud, namely,

$$
\begin{aligned}
C_{T}(x): U \longrightarrow[0,1] & \\
& \forall x \in X(X \subseteq U), x \longrightarrow C_{T}(x) .
\end{aligned}
$$

The Cloud model highlights three numerical characteristics: expectation Ex, entropy En, and hyper entropy He. Figure 1 depicts figure characteristics for the Cloud. The horizontal axis represents the range of uncertainty quantification. The vertical axis represents the degree of membership.

Expectations are the center of the field, the point best able to represent the qualitative concept, always part of this qualitative concept. Reflected in the Cloud is the highest point, whose degree of membership is 1 .

Entropy En represents a range of qualitative concepts that can be measured. The greater En is, the broader spectrum of measurement will be [17]. Entropy reflects the fuzziness of the fuzzy concept, that is, the uncertainty and fuzziness of the qualitative concept.

Hyper entropy is the entropy of itself, used to represent the uncertainty, reflecting the randomness the samples express, also known as Cloud droplet dispersion degree. Super entropy associated fuzziness with randomness, reflected in the Cloud as "thickness"; that is, the greater the He gets, the thicker the Cloud will be.

Cloud model, as a type of transformation model, realizes the convention from qualitative concept to numerical value. Its uniqueness lies in portability; three digital values fully integrate the fuzziness and randomness of qualitative representation [18], of which the Cloud model presents linguistic value, generalizing the feature of linguistic value with that of the Cloud model. In this way, fuzziness and randomness are correlated. In the end, conversion of the uncertainty of qualitative to quantitative data is available.

3.2. DEA Model Based on Energy Efficiency Diagnosis. DEA [19] is put forward by Charnes and Cooper on the basis of efficiency evaluation method. It is an overlapping research across operations research, management science, and quantitative economics. Mathematical programming methods 
are adopted to evaluate decision making units (DMUs) by comprehensive analysis of input and output ratio, so as to determine whether the DMU is efficient or not navigating the landscape for the improvement. The result navigates the landscape for the improvement. DEA is characterized by inclusiveness of the input and output indexes, which can ensure the integrity of the original information while greatly simplifying the measurement process, possessing high sensitivity and reliability.

$C^{2} R$ is perceived as an essential model of DEA method [20-23], an overall effectiveness evaluation model to assess technical efficiency and scale efficiency. In general, $C^{2} R$ can be categorized into two groups: models based on inputs and models based on outputs. The aim of the study is to investigate energy efficiency improvement of thermal power plant, so DEA $-C^{2} R$ is more appropriate.

Firstly, there are $n$ decision making units $\mathrm{DMU}_{j}(1 \leq j \leq$ $n)$. The amount of input indicators is $i(1 \leq i \leq m)$ and that of output indicators is $r(1 \leq r \leq s)$, respectively. The input and output vectors of $\mathrm{DMU}_{j}$ are

$$
\begin{gathered}
X_{j}=\left(x_{1 j}, x_{2 j}, \ldots, x_{m j}\right)^{T}>0, \quad j=1, \ldots, n, \\
Y_{j}=\left(y_{1 j}, y_{2 j}, \ldots, y_{m j}\right)^{T}>0, \quad j=1, \ldots, n .
\end{gathered}
$$

At the same time, the weight of each input and output index is given as follows:

$$
\begin{aligned}
& V=\left(v_{1}, v_{2}, \ldots, v_{m}\right)^{T}>0, \\
& U=\left(u_{1}, u_{2}, \ldots, u_{m}\right)^{T}>0 .
\end{aligned}
$$

The weight vectors are regarded as variables, and their values are determined in the analysis process. First of all, define efficiency evaluation index:

$$
h_{j}=\frac{U^{T} Y_{j}}{V^{T} X_{j}}=\frac{\sum_{r=1}^{s} u_{r} y_{r j}}{\sum_{i=1}^{m} v_{i} x_{i j}} \quad(j=1, \ldots, n) .
$$

For the efficiency evaluation index of the $j$ th decision making unit $\mathrm{DMU}_{j}$, set the weight coefficient as $v$ and $u$ to make $h_{j} \leq 1$. Assuming the input and output as $\left(x_{j}, y_{j}\right)$, then the efficiency evaluation index is $h_{j}\left(h_{j} \leq 1\right)$. Thus the larger $h_{j}$, the smaller input $\mathrm{DMU}_{j}$ plunged into. To identify whether $\mathrm{DMU}_{j}$ is optimal among these DMUs, maximum value can be confirmed with the variation of $v$ and $u$.

Taking $h_{j}$ as objective, build the following $C^{2} R$ model:

$$
\begin{array}{ll}
\max & =\frac{\sum_{r=1}^{s} u_{r} y_{r j}}{\sum_{i=1}^{m} v_{i} x_{i j}}=V \bar{p} \\
\text { s.t. } & \frac{\sum_{r=1}^{s} u_{r} y_{r j}}{\sum_{i=1}^{m} v_{i} x_{i j}} \leq 1, \quad j=1, \ldots, n, \\
& u_{r} \geq 0, \quad r=1, \ldots, s, \\
& v_{i} \geq 0, \quad i=1, \ldots, m .
\end{array}
$$

The optimal value proves to be the optimal efficiency evaluation index. With Charnes-Cooper transformation, (13) transforms from fractional programming to a linear programming form:

$$
\begin{array}{ll}
\max & \mu^{T} Y_{0}=V_{p} \\
\text { s.t. } & \bar{\omega} X_{j}-\mu^{T} Y_{j} \geq 0, \quad j=1, \ldots, n, \\
& \bar{\omega} X_{0}=1 \\
& \omega \geq 0 \\
& \mu \geq 0
\end{array}
$$

According to the duality theory of linear programming, the slack variables are introduced into the dual programming model. $s^{+} \geq 0, s^{-} \geq 0, s^{+}=\left(s_{1}{ }^{+}, s_{2}{ }^{+}, \ldots, s_{s}{ }^{+}\right), s^{-}=$ $\left(s_{1}{ }^{-}, s_{2}{ }^{-}, \ldots, s_{m}{ }^{-}\right)$turn into the following linear programming model:

$$
\begin{array}{ll}
\min & \theta=V_{D} \\
\text { s.t. } & \sum_{j=1}^{n} \lambda_{j} X_{j}+s^{-}=Y_{0}, \\
& \lambda_{j} \geq 0, \quad j=1, \ldots, n, \\
& s^{+} \geq 0 \\
& s^{-} \geq 0
\end{array}
$$

In order to simplify the solving process, a little change of the model can be made to simplify the testing process. Due to the introduction of non-Archimedes infinitesimal variable [24], the following models can be obtained:

$$
\begin{array}{ll}
\min & {\left[\theta-\varepsilon\left(\hat{e}^{T} s^{-}+e^{T} s^{+}\right)\right]=V_{D_{\varepsilon}}} \\
\text { s.t. } & \sum_{j=1}^{n} \lambda_{j} X_{j}+s^{-}=\theta X_{0}, \\
& \sum_{j=1}^{n} \lambda_{j} Y_{j}-s^{+}=Y_{0}, \\
& \lambda_{j} \geq 0, \quad j=1, \ldots, n, \\
& s^{+} \geq 0, \\
& s^{-} \geq 0 .
\end{array}
$$

In the equation, $\varepsilon$ is one figure in the extension of the real number field, less than any positive real number but also greater than zero. In calculation, it is generally taken as $10^{-10}$. $e=(1, \ldots, 1) T \in R_{m}, e=(1, \ldots, 1) T \in R_{s}$.

In the linear programming model, the optimal value $V_{D}$ equals 1 . For each optimal solution, $\lambda^{*}, s^{*-}, s^{*+}, \theta^{*}$, if there exist $\theta^{*}=0, s^{*-}=0, s^{*+}=0$, then $\mathrm{DMU}_{D}$ is effective under DEA; if only they meet the condition that the optimal value equals 1 , then $\mathrm{DMU}_{D}$ is weakly effective under DEA. 
$\theta_{j}$ stands for the technical efficiency of the $j$ th decision making unit. $\theta^{*}=1$ means, for given output $y_{0}$, the input $x_{0}$ cannot be proportionally reduced, that is, $x_{0}$ down to the minimum value. But if $\theta^{*}<1$ means that actual investment can be diminished by the ratio of $\theta^{*}$, then $s^{*-} \neq 0$ is said to be excessive input for the same output and $s^{*+} \neq 0$ expresses the opposite. Corresponding adjustments should be made to achieve DEA effective value.

With the application of DEA model based on $C^{2} R$ to assess the efficiency evaluation of thermal power enterprises, if optimal value is 1, its suggested scale and technology are DEA-efficient at the same time; if the optimal value is less than 1 , then DEA is weekly efficient. According to the analysis of model (16), determine whether technology and scale are valid or not; if invalid, it indicates that the energy efficiency management of enterprises at present is still inadequate and there remains space to improve. Furthermore, with reference to DEA effective value, adjust the input indicators to correct energy efficiency indicators for the sake of effectiveness and practicability.

3.3. The Effectiveness of the Comprehensive Energy Efficiency Diagnosis Model Based on Cloud Model and DEA Model. Data envelopment analysis can achieve more efficiency index evaluation purposes, and it also can conduct more accurate influence power diagnostic on indicator. However, this method needs quantitative indicators. Cloud model quantifies the qualitative indicators, which can improve the reliability of the weights and overcome drawbacks of contrary conventional qualitative and quantitative transformation in human cognitive processes. Basing on Cloud model and DEA model, this paper constructs a comprehensive energy diagnostic model. By implementing the integration and unity of fuzziness and randomness, it can ensure the scientificalness and comprehensiveness during the energy efficiency diagnosis process. Specific steps are as follows.

Step 1 (index system). Select the qualitative and quantitative indicators which can impact on the energy efficiency management. Then establish a factors index system which combines qualitative and quantitative indicators.

Step 2 (cloud the qualitative variables). The value of qualitative variable $U$ is usually assigned by experts' comment. In the process of reverse variable Cloud, conducting Cloud description on qualitative concept by process $p$, including obtaining the Cloud digital feature (Ex, En, He) and the Cloud shape, this model can get clouding of the qualitative variables in realization. $n$ Cloud models including qualitative variables assigned by $N$ experts can be expressed by a comprehensive Cloud, and its digital feature can be derived by the following formula:

$$
\begin{aligned}
& \mathrm{Ex}=\frac{\mathrm{Ex}_{1} * \mathrm{En}_{1}+\mathrm{Ex}_{2} * \mathrm{En}_{2}+\cdots+\mathrm{Ex}_{n} * \mathrm{Ex}_{n}}{\mathrm{En}_{1}+\mathrm{En}_{2}+\cdots+\mathrm{En}_{n}}, \\
& \mathrm{En}=\mathrm{En}_{1}+\mathrm{En}_{2}+\cdots+\mathrm{En}_{n}, \\
& \mathrm{He}=\frac{\mathrm{He}_{1} * \mathrm{He}_{1}+\mathrm{He}_{2} * \mathrm{He}_{2}+\cdots+\mathrm{He}_{n} * \mathrm{He}_{n}}{\mathrm{En}_{1}+\mathrm{En}_{2}+\cdots+\mathrm{En}_{n}} .
\end{aligned}
$$

Step 3 (conversion of qualitative input to quantitative output). (1) Assume that there are $n$ qualitative indicators which constitute $X=\left(x_{1}, x_{2}, \ldots, x_{n}\right)$. Based on the unified standard $c_{i}$, conduct membership $\alpha_{i}(0<\alpha<1)$ of each index which is established by experts. Then, the membership of relative standard value of the $i$ th nonquantitative indicators is $\alpha_{i}$, and the memberships of relative standard value of all indicators are $\left(\alpha_{1}, \alpha_{2}, \ldots, \alpha_{n}\right)$. Take these Cloud droplets as input, and use estimation algorithm to restore the final Cloud digital feature (Ex, En, He). Then matrix $A$ is obtained.

$$
A=\left[\begin{array}{ccc}
\mathrm{Ex}_{\alpha_{1}} & \mathrm{En}_{\alpha_{1}} & \mathrm{He}_{\alpha_{1}} \\
\mathrm{Ex}_{\alpha_{2}} & \mathrm{En}_{\alpha_{2}} & \mathrm{He}_{\alpha_{2}} \\
\vdots & \vdots & \vdots \\
\mathrm{Ex}_{\alpha_{n}} & \mathrm{En}_{\alpha_{n}} & \mathrm{He}_{\alpha_{n}}
\end{array}\right]^{T} .
$$

Among them,

$$
\begin{aligned}
& \mathrm{Ex}=\bar{X}, \\
& \mathrm{En}=\sqrt{\frac{1}{2} \frac{1}{n} \sum_{i=1}^{n}\left|x_{i}-\mathrm{Ex}\right|,} \\
& \mathrm{He}=\sqrt{\left|S^{2}-\mathrm{En}^{2}\right|} .
\end{aligned}
$$

After several cycles, this paper gets the final desired value matrix $A$, and it is the quantitative conversion result of qualitative inputs.

(2) Assign the weight according to experts' assessment. In order to reduce the subjectivity of experts' weighting, this paper estimated again the weight of index to determine the Cloud digital feature $\left(\mathrm{Ex}^{\prime}, \mathrm{En}^{\prime}, \mathrm{He}^{\prime}\right)$ of weights and obtain weight matrix $R$.

$$
R=\left[\begin{array}{ccc}
\mathrm{Ex}_{1} & \mathrm{En}_{1} & \mathrm{He}_{1} \\
\mathrm{Ex}_{2} & \mathrm{En}_{2} & \mathrm{He}_{2} \\
\vdots & \vdots & \vdots \\
\mathrm{Ex}_{n} & \mathrm{En}_{n} & \mathrm{He}_{n}
\end{array}\right] .
$$

(3) Calculate nonquantifiable indicators by using calculation method of Fuzzy Composite Operators in multiplying and bounded operator [25] and combining with Cloud algorithms. Then this paper obtains the final Cloud digital feature analysis results which can fully reflect the qualitative factors trait, and the results are regarded as matrix $B$. 
TABLE 5: Cloud computing rule.

\begin{tabular}{lccc}
\hline & $\mathrm{Ex}$ & $\mathrm{En}$ & $\sqrt{\mathrm{He}_{1}{ }^{2}+\mathrm{He}_{2}{ }^{2}}$ \\
\hline+ & $\mathrm{Ex}_{1}+\mathrm{Ex}_{2}$ & $\sqrt{\mathrm{En}_{1}{ }^{2}+\mathrm{En}_{2}{ }^{2}}$ & $\sqrt{\mathrm{He}_{1}{ }^{2}+\mathrm{He}_{2}{ }^{2}}$ \\
\hline$*$ & $\mathrm{Ex}_{1}-\mathrm{Ex}_{2}$ & $\sqrt{\mathrm{En}_{1}{ }^{2}+\mathrm{En}_{2}{ }^{2}}$ & $\left|\mathrm{Ex}_{1} \mathrm{Ex}_{2}\right| \sqrt{\left(\frac{\mathrm{He}_{1}}{\mathrm{Ex}_{1}}\right)^{2}+\left(\frac{\mathrm{He}_{2}}{\mathrm{Ex}_{2}}\right)^{2}}$ \\
\hline$\div$ & $\mathrm{Ex}_{1} * \mathrm{Ex}_{2}$ & $\left|\mathrm{Ex}_{1} \mathrm{Ex}_{2}\right| \sqrt{\left(\frac{\mathrm{En}_{1}}{\mathrm{Ex}_{1}}\right)^{2}+\left(\frac{\mathrm{En}_{2}}{\mathrm{Ex}_{2}}\right)^{2}}$ & $\left|\frac{\mathrm{Ex}_{1}}{\mathrm{Ex}_{2}}\right| \sqrt{\left(\frac{\mathrm{He}_{1}}{\mathrm{Ex}_{1}}\right)^{2}+\left(\frac{\mathrm{He}_{1} \mathrm{He}_{2}}{\left.\mathrm{Ex}_{2}\right)^{2}}\right.}$ \\
\hline
\end{tabular}

$$
\begin{aligned}
& B=A \circ R=\left[\begin{array}{ccc}
\mathrm{Ex}_{\alpha_{1}} & \mathrm{En}_{\alpha_{1}} & \mathrm{He}_{\alpha_{1}} \\
\mathrm{Ex}_{\alpha_{2}} & \mathrm{En}_{\alpha_{2}} & \mathrm{He}_{\alpha_{2}} \\
\vdots & \vdots & \vdots \\
\mathrm{Ex}_{\alpha_{n}} & \mathrm{En}_{\alpha_{n}} & \mathrm{He}_{\alpha_{n}}
\end{array}\right]^{T} \circ\left[\begin{array}{ccc}
\mathrm{Ex}_{1} & \mathrm{En}_{1} & \mathrm{He}_{1} \\
\mathrm{Ex}_{2} & \mathrm{En}_{2} & \mathrm{He}_{2} \\
\vdots & \vdots & \vdots \\
\mathrm{Ex}_{n} & \mathrm{En}_{n} & \mathrm{He}_{n}
\end{array}\right]
\end{aligned}
$$

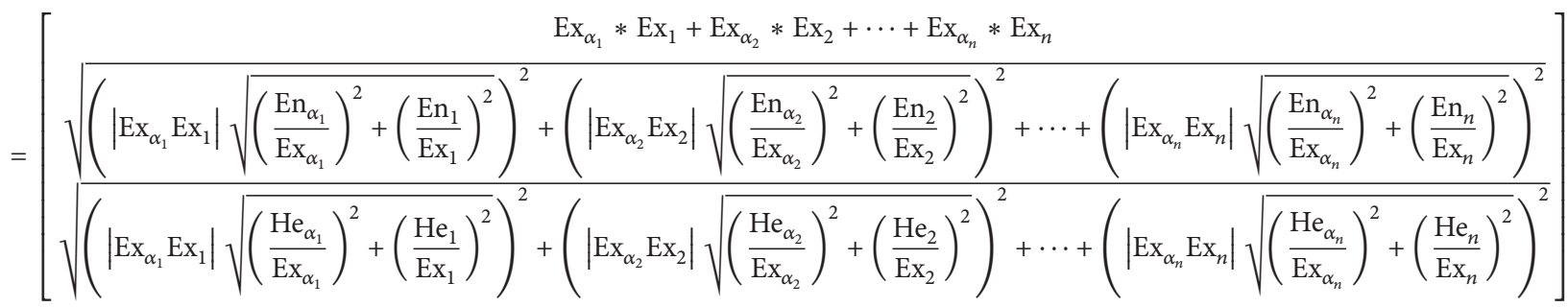

$$
\begin{aligned}
& =\left(\mathrm{Ex}_{0}, \mathrm{En}_{0}, \mathrm{He}_{0}\right)^{T} \text {. }
\end{aligned}
$$

The rules of Cloud computing used above are shown in Table 5 [26].

Through the above steps, this paper obtains a Cloud digital feature analytical result $\left(\mathrm{Ex}_{0}, \mathrm{En}_{0}, \mathrm{He}_{0}\right)^{T}$ based on Cloud quantization process, namely, comprehensive quantitative result of qualitative indicators.

Step 4 (diagnosis and analysis of model). Input the qualitative and quantitative indicators to get the final output indicators, and conduct energy efficiency diagnosis and analysis.

\section{Empirical Analysis}

Firstly, this paper establishes a management index system combining qualitative and quantitative factors. Then, based on the Cloud model [10] and DEA model [11] (Cloud model can quantify qualitative indicators reasonably, and DEA model has obvious advantages in evaluating generation enterprise multiefficiency indicators), it carries out empirical analysis of data, by selecting the 2014 data of $300 \mathrm{MW}$ units from Hebei Guohua Huanghua Power Plant (hereinafter referred to as Plant A), Kunming Second Power Plant (hereinafter referred to as Plant B), and Zhongfu Power Plant (hereinafter referred to as Plant C).
4.1. Indicator Definitions and Data Sources. By constructing the index system, the 11 input indicators are determined as follows: boiler thermal efficiency, turbine thermal efficiency, pipeline efficiency, power consumption rate, loading rate, the degree of water reuse, recycling water system operation optimization, operating equipment advanced degree, coalfired admission management level, the unit operation and management level, efforts to implement energy efficiency policies, and so forth, and output indicators are generation coal consumption and power supply coal consumption.

Taking into account the characteristics of qualitative and quantitative indicators, quantitative indicators of data are derived from field researches, related Technical Agreement (Boiler Technology Agreement, Turbo Technology Agreement, etc.) of Hebei Guohua Huanghua Power Plant and annual reports, and so forth; qualitative indicators data sources are derived from field researches, statistical calculations, and technical experts' advisory from all of the above three power plants.

\subsection{Basic Data Processing}

4.2.1. Quantitative Data Processing. By querying data and field researches about the normal condition of $300 \mathrm{MW}$ units of three power plants, data of 2014 is regarded as the basis for 
TABLE 6: Plant raw data.

\begin{tabular}{|c|c|c|c|c|}
\hline Indicator & Unit & Plant A & Plant B & Plant C \\
\hline Exhaust loss & $\%$ & 4.66 & 5.75 & 6.68 \\
\hline Gas incomplete combustion loss & $\%$ & 0.18 & 0 & 1.06 \\
\hline Solid incomplete combustion loss & $\%$ & 0.70 & 3.02 & 2.74 \\
\hline Heat loss & $\%$ & 0.17 & 0.27 & 0.49 \\
\hline Ash physical heat loss & $\%$ & 0.35 & 0.33 & 0.14 \\
\hline Heat consumption & $\mathrm{kJ} /(\mathrm{kW} \cdot \mathrm{h})$ & 8203.04 & 8227.18 & 8184 \\
\hline Boiler heat input & $\mathrm{GJ} / \mathrm{h}$ & 6319.11 & - & - \\
\hline Boiler heat output & $\mathrm{GJ} / \mathrm{h}$ & 5936.07 & - & - \\
\hline Turbine heat input & $\mathrm{GJ} / \mathrm{h}$ & 5904.61 & - & - \\
\hline The average unit load & MW & - & 270.15 & - \\
\hline Maximum load unit & MW & - & 304.64 & - \\
\hline Power supply standard coal consumption & $\mathrm{g} /(\mathrm{kW} \cdot \mathrm{h})$ & 315.69 & 346.32 & 357 \\
\hline Generation standard coal consumption & $\mathrm{g} /(\mathrm{kW} \cdot \mathrm{h})$ & 300.69 & 306.42 & 324.6 \\
\hline
\end{tabular}

TABLE 7: Raw data calculations.

\begin{tabular}{lcccc}
\hline Indicator & Unit & Plant A & Plant B & Plant C \\
\hline Boiler thermal efficiency & $\%$ & 93.94 & 90.63 & 97.90 \\
Turbine thermal efficiency & $\%$ & 98.95 & 98.97 & 98.24 \\
Pipeline efficiency & $\%$ & 99.47 & 98.68 & 99.01 \\
Power consumption rate & $\%$ & 5.03 & 7.57 & 9.11 \\
Loading rate & $\%$ & 85.17 & 88.68 & 83.00 \\
\hline
\end{tabular}

TABLE 8: Membership of qualitative indicators.

\begin{tabular}{|c|c|c|c|c|c|c|}
\hline & $\begin{array}{l}\text { The degree of } \\
\text { water reuse }\end{array}$ & $\begin{array}{l}\text { Recycling water } \\
\text { system operation } \\
\text { optimization }\end{array}$ & $\begin{array}{c}\text { Operating } \\
\text { equipment } \\
\text { advanced degree }\end{array}$ & $\begin{array}{c}\text { Coal-fired } \\
\text { admission } \\
\text { management level }\end{array}$ & $\begin{array}{c}\text { The unit } \\
\text { operation and } \\
\text { management level }\end{array}$ & $\begin{array}{c}\text { Efforts to } \\
\text { implement } \\
\text { energy efficiency } \\
\text { policies }\end{array}$ \\
\hline Expert 1 & 0.85 & 0.90 & 0.75 & 0.85 & 0.75 & 0.60 \\
\hline Expert 2 & 0.80 & 0.85 & 0.70 & 0.85 & 0.70 & 0.70 \\
\hline Expert 3 & 0.80 & 0.90 & 0.70 & 0.80 & 0.75 & 0.70 \\
\hline Expert 4 & 0.75 & 0.95 & 0.70 & 0.85 & 0.75 & 0.65 \\
\hline Expert 5 & 0.80 & 0.90 & 0.65 & 0.70 & 0.80 & 0.60 \\
\hline Expert 6 & 0.75 & 0.85 & 0.65 & 0.85 & 0.75 & 0.65 \\
\hline Expert 7 & 0.80 & 0.90 & 0.60 & 0.80 & 0.80 & 0.60 \\
\hline Expert 8 & 0.80 & 0.90 & 0.70 & 0.90 & 0.80 & 0.70 \\
\hline Expert 9 & 0.75 & 0.95 & 0.75 & 0.75 & 0.75 & 0.75 \\
\hline Expert 10 & 0.85 & 0.95 & 0.65 & 0.70 & 0.85 & 0.80 \\
\hline
\end{tabular}

the initial analysis of the model to obtain the raw index data (see Table 6).

Combined with the original data, calculate the index data according to the formulas. Results are shown in Table 7.

4.2.2. Qualitative Data Processing. In considering the characteristics of indicators and data availability, determine the weight in accordance with expert assessment, and quantify qualitative indicators by the Cloud model. A case study with Plant A invited 10 experts to score 6 qualitative indicators, including water reuse degree, circulating water system operation optimization, operating equipment advanced degree, coal-fired admission management level, the unit operation and management level, and efforts to implement energy efficiency policy. Firstly, set the memberships of six indicators with respect to the standard value 1 by the experts; the results are shown in Table 8 .

Using estimation algorithm, Cloud digital features of various qualitative indicators of Plant $\mathrm{A}$ are determined. The calculation results are shown in Table 9. 
TABLE 9: Qualitative indicators Cloud digital features.

\begin{tabular}{|c|c|c|c|c|c|c|}
\hline & $\begin{array}{l}\text { The degree of } \\
\text { water reuse }\end{array}$ & $\begin{array}{l}\text { Recycling water } \\
\text { system operation } \\
\text { optimization }\end{array}$ & $\begin{array}{c}\text { Operating } \\
\text { equipment } \\
\text { advanced degree }\end{array}$ & $\begin{array}{c}\text { Coal-fired } \\
\text { admission } \\
\text { management level }\end{array}$ & $\begin{array}{l}\text { The unit } \\
\text { operation and } \\
\text { management level }\end{array}$ & $\begin{array}{c}\text { Efforts to } \\
\text { implement } \\
\text { energy efficiency } \\
\text { policies }\end{array}$ \\
\hline Ex & 0.795 & 0.905 & 0.685 & 0.805 & 0.77 & 0.675 \\
\hline S & 0.001361 & 0.001361 & 0.00225 & 0.004694 & 0.001778 & 0.004583 \\
\hline En & 0.021216 & 0.007858 & 0.007072 & 0.007858 & 0.015323 & 0.008644 \\
\hline $\mathrm{He}$ & 0.030182 & 0.036047 & 0.046904 & 0.068064 & 0.039281 & 0.067146 \\
\hline
\end{tabular}

TABLE 10: Experts on Plant A qualitative indicators assignment.

\begin{tabular}{|c|c|c|c|c|c|c|}
\hline & $\begin{array}{l}\text { The degree of } \\
\text { water reuse }\end{array}$ & $\begin{array}{l}\text { Recycling water } \\
\text { system operation } \\
\text { optimization }\end{array}$ & $\begin{array}{c}\text { Operating } \\
\text { equipment } \\
\text { advanced degree }\end{array}$ & $\begin{array}{c}\text { Coal-fired } \\
\text { admission } \\
\text { management level }\end{array}$ & $\begin{array}{c}\text { The unit } \\
\text { operation and } \\
\text { management level }\end{array}$ & $\begin{array}{c}\text { Efforts to } \\
\text { implement } \\
\text { energy efficiency } \\
\text { policies } \\
\end{array}$ \\
\hline Expert 1 & 65 & 80 & 45 & 85 & 80 & 80 \\
\hline Expert 2 & 70 & 75 & 50 & 90 & 90 & 75 \\
\hline Expert 3 & 65 & 70 & 50 & 90 & 85 & 85 \\
\hline Expert 4 & 65 & 75 & 50 & 85 & 85 & 70 \\
\hline Expert 5 & 70 & 60 & 45 & 80 & 80 & 80 \\
\hline Expert 6 & 55 & 75 & 40 & 85 & 95 & 75 \\
\hline Expert 7 & 60 & 60 & 40 & 90 & 90 & 70 \\
\hline Expert 8 & 60 & 70 & 50 & 85 & 80 & 85 \\
\hline Expert 9 & 55 & 75 & 45 & 85 & 85 & 80 \\
\hline Expert 10 & 65 & 75 & 55 & 95 & 80 & 85 \\
\hline
\end{tabular}

TABLE 11: Cloud digital signature of qualitative indicators weights.

\begin{tabular}{|c|c|c|c|c|c|c|}
\hline & $\begin{array}{l}\text { The degree of } \\
\text { water reuse }\end{array}$ & $\begin{array}{l}\text { Recycling water } \\
\text { system operation } \\
\text { optimization }\end{array}$ & $\begin{array}{c}\text { Operating } \\
\text { equipment } \\
\text { advanced degree }\end{array}$ & $\begin{array}{c}\text { Coal-fired } \\
\text { admission } \\
\text { management level }\end{array}$ & $\begin{array}{c}\text { The unit } \\
\text { operation and } \\
\text { management level }\end{array}$ & $\begin{array}{c}\text { Efforts to } \\
\text { implement } \\
\text { energy efficiency } \\
\text { policies }\end{array}$ \\
\hline Ex & 63 & 71.5 & 47 & 87 & 85 & 78.5 \\
\hline S & 28.88889 & 44.72222 & 23.33333 & 17.77778 & 27.77778 & 33.61111 \\
\hline En & 3.457489 & 4.086123 & 3.143171 & 2.671696 & 3.143171 & 3.771806 \\
\hline $\mathrm{He}$ & 4.115175 & 5.293942 & 3.667943 & 3.261874 & 4.230632 & 4.402794 \\
\hline
\end{tabular}

Then this paper obtains the Cloud digital feature matrix $A$ of qualitative indicators as follows:

$$
A=\left(\begin{array}{ccc}
0.795 & 0.0212 & 0.0301 \\
0.905 & 0.0079 & 0.0360 \\
0.685 & 0.0071 & 0.0469 \\
0.805 & 0.0079 & 0.0681 \\
0.77 & 0.0153 & 0.0393 \\
0.675 & 0.0086 & 0.0671
\end{array}\right) .
$$

Through field researches, the expert evaluation method is reused to determine the weight of nonquantifiable indicators. 10 experts assign weights of the six indicators of Plant A, according to the external conditions which influence the change of each factor. The full mark is 100, the maximum mark is 100, and minimum mark is 0 . By assignment, we can evaluate all aspects in operation of Plant A. Table 10 shows the cases that experts assigned.

Likewise, the Cloud digital features of the weight are as shown in Table 11.

The Cloud digital features matrix of the weights of qualitative indicators can be expressed as follows:

$$
R=\left(\begin{array}{ccc}
63 & 3.4575 & 4.1152 \\
71.5 & 4.0861 & 5.2939 \\
47 & 3.1432 & 3.6679 \\
87 & 2.6717 & 3.2619 \\
85 & 3.1432 & 4.2306 \\
78.5 & 3.7718 & 4.4028
\end{array}\right)
$$


Finally, the Cloud algorithm obtains the overall Cloud digital features of qualitative indicators of Plant A:

$$
\begin{aligned}
& B=R^{T} \circ A \\
& =\left(\begin{array}{ccc}
63 & 3.4575 & 4.1152 \\
71.5 & 4.0861 & 5.2939 \\
47 & 3.1432 & 3.6679 \\
87 & 2.6717 & 3.2619 \\
85 & 3.1432 & 4.2306 \\
78.5 & 3.7718 & 4.4028
\end{array}\right)^{T} \\
& \circ\left(\begin{array}{ccc}
0.795 & 0.0212 & 0.0301 \\
0.905 & 0.0079 & 0.0360 \\
0.685 & 0.0071 & 0.0469 \\
0.805 & 0.0079 & 0.0681 \\
0.77 & 0.0153 & 0.0393 \\
0.675 & 0.0086 & 0.0671
\end{array}\right) \\
& =(335.46,16.6150,9.7568)^{T} .
\end{aligned}
$$

Similarly, the qualitative indicators of Plant B and Plant $\mathrm{C}$ are quantified. The final diagnosis obtains basic data of the three power plants, as shown in Table 12.

\subsection{Diagnosis and Analysis of Energy Efficiency}

4.3.1. The Energy Efficiency Diagnosis Which Only Considers the Productive Operational Parameters. Combined with Table 3, by using the model, through MATLAB software, the quantitative data of the three plants are diagnosed, which only considers the impact of productive operational parameters on energy efficiency management. The matrix of input $X$ and output $Y$ is as shown in Table 13.

Get the relative value efficiency of the power plant: $E 11=$ $0.8898, E 22=1.0000$, and $E 33=0.7568$. By definition, $\mathrm{DMU}_{2}$ at least is weakly effective; $\mathrm{DMU}_{1}$ and $\mathrm{DMU}_{3}$ are noneffective.

4.3.2. Energy Efficiency Diagnosis of Index System Which Is Based on Qualitative and Quantitative Factors. In addition to considering productive operational parameters, the energy saving technologies and the impact of the comprehensive management level are also considered; the input-output matrix is as shown in Table 14.

And $E 11=1.0000, E 22=0.9542$, and $E 33=0.8567$.

Similarly, in the MATLAB software, according to model (14) programming language, the results are as follows:

$$
\begin{aligned}
& E 11=1.0000, \\
& E 22=0.9542, \\
& E 33=0.8567 .
\end{aligned}
$$

It was found that $\mathrm{DMU}_{1}$ is at least weakly effective; $\mathrm{DMU}_{2}$ and $\mathrm{DMU}_{3}$ are nonweakly effective.
TABLE 12: Qualitative indicators integrated cloud digital features of plant.

\begin{tabular}{lccc}
\hline & Ex & En & He \\
\hline Plant A & 335.46 & 16.6150 & 9.7568 \\
Plant B & 317.70 & 15.5593 & 10.8217 \\
Plant C & 183.5930 & 26.0128 & 8.4438 \\
\hline
\end{tabular}

TABLE 13: Input and output conditions of quantitative variables.

\begin{tabular}{lccc}
\hline & $\mathrm{DMU}_{1}$ & $\mathrm{DMU}_{2}$ & $\mathrm{DMU}_{3}$ \\
\hline$X 1$ & 93.94 & 90.63 & 87.90 \\
$X 2$ & 98.95 & 98.97 & 98.24 \\
$X 3$ & 99.47 & 98.68 & 99.01 \\
$X 4$ & 5.03 & 7.57 & 9.11 \\
$X 5$ & 85.17 & 88.68 & 83.00 \\
$Y 1$ & 315.69 & 346.32 & 357 \\
$Y 2$ & 300.69 & 306.42 & 324.6 \\
\hline
\end{tabular}

TABLE 14: The input and output conditions of quantitativequalitative variables.

\begin{tabular}{lccc}
\hline & $\mathrm{DMU}_{1}$ & $\mathrm{DMU}_{2}$ & $\mathrm{DMU}_{3}$ \\
\hline$X 1$ & 93.94 & 90.63 & 87.90 \\
$X 2$ & 98.95 & 98.97 & 98.24 \\
$X 3$ & 99.47 & 98.68 & 99.01 \\
$X 4$ & 5.03 & 7.57 & 9.11 \\
$X 5$ & 85.17 & 88.68 & 83.00 \\
$X 6(\mathrm{Ex})$ & 335.46 & 317.70 & 183.5930 \\
$X 7(\mathrm{En})$ & 16.6150 & 15.5593 & 26.0128 \\
$X 8(\mathrm{He})$ & 9.7568 & 10.8217 & 8.4438 \\
$Y 1$ & 315.69 & 346.32 & 357 \\
$Y 2$ & 300.69 & 306.42 & 324.6 \\
\hline
\end{tabular}

To further confirm the reason that $\mathrm{DMU}_{2}$ and $\mathrm{DMU}_{3}$ are nonweakly effective, this paper uses model (16) to get DEA diagnostic results, which are shown in Table 15.

\subsection{Analysis of Energy Efficiency Diagnosis}

4.4.1. Verification of the Rationality of the Diagnostic Model. By comparing the results of DEA diagnosis, it can be found that the ranking results of energy efficiency are different when only considering productive operational parameters indicators and when comprehensively considering qualitative and quantitative indicators. When diagnosing the energy efficiency based on only quantitative indicators, the energy efficiency order of the three plants is as follows: Plant B > Plant A > Plant C, which is changed to "Plant A > Plant B $>$ Power C" after bringing in qualitative indicators' Cloud digital feature (Ex, En, He) processed by the Cloud model.

While in actual production, by using Shenhua coal, which is transported to Huanghua Port by Shenhuang Railway and then transferred to the power plant by the conveyor belt, Plant A (Hebei Guohua Huanghua Power Plant) achieves a scientific management of coal combustion, and its circulation of cooling water is optimized by using the way of seawater 
TABLE 15: The results of DEA diagnosis.

\begin{tabular}{lcccccc}
\hline $\mathrm{DMU}$ & $\theta^{*}$ & $\lambda^{*}$ & Technical efficiency & $\lambda^{*} \theta_{1}{ }^{*}$ & Returns to scale & DEA effectiveness \\
\hline $\mathrm{DMU}_{1}(\mathrm{~A})$ & 1 & 1 & Valid & 1 & Constant & Valid \\
$\mathrm{DMU}_{2}(\mathrm{~B})$ & 0.9542 & 0.9238 & Invalid & 0.9681 & Increasing & Invalid \\
$\mathrm{DMU}_{3}(\mathrm{C})$ & 0.8567 & 0.8328 & Invalid & 0.9721 & Increasing & Invalid \\
\hline
\end{tabular}

TABLE 16: Plant B and Plant C results of economic evaluation.

\begin{tabular}{|c|c|c|c|c|c|c|c|}
\hline & & \multicolumn{6}{|c|}{$\mathrm{DMU}$} \\
\hline & & \multicolumn{3}{|c|}{$\mathrm{DMU}_{2}($ Plant B $)$} & \multicolumn{3}{|c|}{$\mathrm{DMU}_{3}($ Plant C $)$} \\
\hline & & Current value & Improved value & Difference & Current value & Improved value & Difference \\
\hline \multirow{8}{*}{ Input } & $X 1$ & 90.63 & 92.94 & 2.31 & 87.90 & 89.93 & 2.03 \\
\hline & $X 2$ & 98.97 & 99.05 & 0.08 & 98.24 & 98.76 & 0.52 \\
\hline & $X 3$ & 98.68 & 98.97 & 0.29 & 99.01 & 99.03 & 0.02 \\
\hline & $X 4$ & 7.57 & 6.03 & -1.54 & 9.11 & 7.24 & -1.87 \\
\hline & $X 5$ & 88.68 & 89.17 & 0.49 & 83.00 & 84.69 & 1.69 \\
\hline & $X 6$ & 317.70 & 335.46 & 17.76 & 183.5930 & 184.1526 & 0.5596 \\
\hline & $X 7$ & 15.5593 & 16.6150 & 1.0557 & 26.0128 & 27.4112 & 1.3984 \\
\hline & $X 8$ & 10.8217 & 11.7568 & 0.9351 & 8.4438 & 8.8935 & 0.4497 \\
\hline \multirow{2}{*}{ Output } & $Y 1$ & 346.32 & 346.32 & 0 & 357 & 357 & 0 \\
\hline & $Y 2$ & 306.42 & 306.42 & 0 & 324.6 & 324.6 & 0 \\
\hline
\end{tabular}

once-through cooling from the Huanghua harbor basin. In addition, Plant A brings in the Wet Limestone-Gypsum Flue Gas Desulfurization technology of Germany Lurgi Energy and Environmental Protection Company, making the desulfurization efficiency above $95 \%$.

Through the transformation of the above three aspects, the energy efficiency of Plant A is significantly better than Plant B. Thus, combined with reality, the analysis results of the diagnostic model of thermal power enterprises' energy efficiency management which is based on a combination of qualitative and quantitative indicators are more similar to the real situation, which proves the validity of the model.

4.4.2. Analysis of Diagnostic Results. According to the analysis of the results, when adding the qualitative indicators of Cloud digital features processed by Cloud model, the efficiency value of Plant A increased, reaching DEA effective value, and Plant B changed from being effective to invalid, while Plant C's efficiency increased but it needed to be further strengthened. The following gives the major suggestions for Plant B and Plant C, as shown in Table 16.

Take Plant $\mathrm{B}$ as an example to make the following analysis: the DEA diagnosis of Plant B is invalid, in order to achieve DEA effective value, the ways of reducing the amount of cold air into the boiler, reconstructing the air preheater heat storage element, increasing the heat transfer area of economizer, and reconstructing boiler burning belt should be used. And the boiler thermal efficiency may increase $2.31 \%$. By using cellular contact steam seal, optimizing gas distribution mode, the steam turbine generator set thermal efficiency may increase $0.08 \%$, and pipeline efficiency may increase $0.29 \%$. By reducing pump power consumption and changing the circulating pump control mode to achieve maximum control of circulating water and other ways, the power consumption rate can decrease $1.54 \%$, and the load rate can increase $0.49 \%$

In addition, Plant B is required to increase investment in water reuse degree, advanced degree of operating equipment, coal-fired admission management level, management level of machine set, implementation of energy policy, and so forth, such as phasing out the equipment which has been running for a long time, correcting unreasonable parameters of plant fan, and increasing the design space of flue gas duct to achieve the advancement of major equipment, the scientific management of coal-fired, the refinement of unit operation, and thorough implementation of energy conservation policy.

From the above analysis, it is found that the comprehensive diagnostic model analysis results, which are processed by Cloud model, are more reasonable, compared with the only use of the general quantitative data energy efficiency assessment. On the one hand, a more accurate ranking of plant energy efficiency can be got and it can improve the accuracy of subjective assignment and prove the rationality of the model through empirical analysis; on the other hand, by combining the Cloud model with DEA model, the horizontal comparison of the three power generation companies can be achieved, and relatively targeted recommendations can be made for the power generation company whose energy efficiency is backward. It plays a referential role for the various enterprises in energy saving practical work in the future and proves the validity of the diagnostic model.

\section{Conclusion}

Effective diagnosis and energy management can obviously reduce carbon emissions and overall energy consumption of thermal power enterprises, which can promote the development of the whole industry. This paper analyzes and 
summarizes the factors that affect energy efficiency management from the aspect of actual internal and external environment of energy efficiency management. This method overcomes the defect of previous researches which only considered quantitative indicators and sets diagnosis index system of energy efficiency management of 11 qualitative and quantitative indicators which contains the unit operation and management level, efforts to implement energy efficiency policies, and so forth. Besides, this method combines Cloud model with DEA model into an integrated diagnostic model which is called "CDM." This model was used in actual energy efficiency analysis of thermal power enterprises. The rationality of index system in this paper is verified by comparing quantitative index systems which only consider productive operational parameters. Finally, in order to provide a reference for the same type of enterprises in the actual implementation of the energy efficiency management, this paper puts forward improvements by comparing the effectiveness of three power plants' energy efficiency.

\section{Competing Interests}

The authors declare that there is no conflict of interests regarding the publication of this article.

\section{Acknowledgments}

This paper was supported by the Social Science Foundation of Beijing (Project ID 15JGB050).

\section{References}

[1] M. Wang, Efficiency of Fired Power Plants Investment in Environment Protection Evaluation System and Application, Inner Mongolia University, 2010.

[2] F. Dan, Economic Analysis of Thermal Power Plant Based on Comprehensive Benefit Index, North China Electric Power University, Beijing, China, 2011.

[3] W. H. J. Graus and E. Worrell, "Effects of $\mathrm{SO}_{2}$ and $\mathrm{NO}_{x}$ control on energy-efficiency power generation," Energy Policy, vol. 35, no. 7, pp. 3898-3908, 2007.

[4] N. Shen, J. Zhou, and W. Zou, "Energy efficiency measures and convergence in China, taking into account the effects of environmental and random factors," Polish Journal of Environmental Studies, vol. 24, no. 1, pp. 257-267, 2015.

[5] S. Ludig, E. Schmid, M. Haller, and N. Bauer, "Assessment of transformation strategies for the German power sector under the uncertainty of demand development and technology availability," Renewable and Sustainable Energy Reviews, vol. 46, pp. 143-156, 2015.

[6] C.-Y. Fang, J.-L. Hu, and T.-K. Lou, "Environment-adjusted total-factor energy efficiency of Taiwan's service sectors," Energy Policy, vol. 63, pp. 1160-1168, 2013.

[7] R. Martin, M. Muûls, L. B. De Preux, and U. J. Wagner, "Anatomy of a paradox: management practices, organizational structure and energy efficiency," Journal of Environmental Economics and Management, vol. 63, no. 2, pp. 208-223, 2012.

[8] Y. Cai, B. Li, Z. Hu, Y. Song, and Y. Zhao, "Calculation of carbon emission index of coal-fired generating unit and analysis on influencing factors," Power System Technology, vol. 37, no. 5, pp. 1185-1189, 2013.

[9] U. Schiffers, "Combined gas and steam-turbine power generating station," US Patent 4,697,415, 1987.

[10] H. Jun, Research on Large Thermal Plants Management Mode of Saving Energy, North China Electric Power University, Beijing, China, 2011.

[11] M. Ghadimi, A. Ramezani, and K. Bozorgi, "Energy efficiency and power quality optimization using a modified capacitor bank: An Industrial Case Study," in Proceedings of the UKSim 3rd European Modelling Symposium on Computer Modelling and Simulation (EMS '09), pp. 384-388, November 2009.

[12] L. Deyi, "The cloud control method and balancing patterns of triple link inverted pendulum systems," Engineering Science, vol. 2, pp. 41-46, 1999.

[13] Y. Zhaohui and L. Deyi, "Planar model and its application in prediction," Chinese Computers, vol. 11, pp. 961-969, 1998.

[14] J. Yue, L. Deyi, and Y. Zhaohui, "A new method to evaluate the effectiveness of C 3I system," Systems Engineering-Theory \& Practice, vol. 12, pp. 69-74, 1998.

[15] H. Chen, D. Li, and C. Z. Shen, "A Cloud model applied to controlling inverted pendulum," Journal of Computer Research \& Development, vol. 10, pp. 1180-1187, 1999.

[16] Q. Ye, S.-W. Li, Y.-H. Zhang, X.-W. Shu, and D.-P. Ni, "Cloud model and application overview," Computer Engineering and Design, vol. 3, no. 12, pp. 4198-4201, 2011.

[17] X.-Y. Du, Q.-J. Yin, K.-D. Huang, and D.-N. Liang, "Transformation between qualitative variables and quantity based on cloud models and its application," Systems Engineering and Electronics, vol. 30, no. 4, pp. 772-776, 2008.

[18] A. Charnes, W. W. Cooper, Q. L. Wei, and Z. M. Huang, "Cone ratio data envelopment analysis and multi-objective programming," International Journal of Systems Science, vol. 20, no. 7, pp. 1099-1118, 1989.

[19] Z. Huang and S. X. Li, "Dominance stochastic models in data envelopment analysis," European Journal of Operational Research, vol. 95, no. 2, pp. 390-403, 1996.

[20] L. Wu, Effectiveness Analysis Based on the Size of Institutions of Higher Learning Data Envelopment Analysis (DEA), Tongji University, Shanghai, China, 2006.

[21] C. Kao and S.-T. Liu, "Fuzzy efficiency measures in data envelopment analysis," Fuzzy Sets and Systems, vol. 113, no. 3, pp. 427-437, 2000.

[22] G. Yu, Q. Wei, and P. Brockett, "A generalized data envelopment analysis model: a unification and extension of existing methods for efficiency analysis of decision making units," Annals of Operations Research, vol. 66, no. 2, pp. 47-59, 1996.

[23] S. Su, A Study on the Efficiency of the Listed Companies of Real Estate in China Based on DEA Method, Chongqing University, Chongqing, China, 2007.

[24] S.-L. Ning, L. Chen, and L. Li, "Analyzing fuzzy composite operators for application to command efficiency evaluation," Fire Control and Command Control, vol. 33, no. 12, pp. 117-120, 2008.

[25] Y.-B. Shi, A. Zhang, X.-J. Gao, and Z.-J. Tan, "Cloud model and its application in effectiveness evaluation," in Proceedings of the International Conference on Management Science and Engineering 15th Annual Conference (ICMSE '08), pp. 250-255, September 2008.

[26] S. Rujia, Research on the Index Evaluation System of Thermal Power, North China Electric Power University, Beijing, China, 2011. 


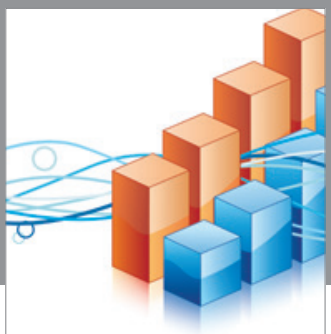

Advances in

Operations Research

vatem alat4

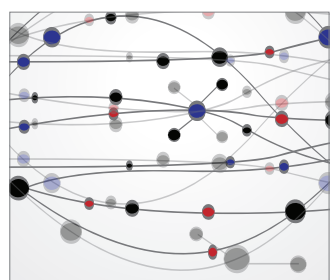

\section{The Scientific} World Journal
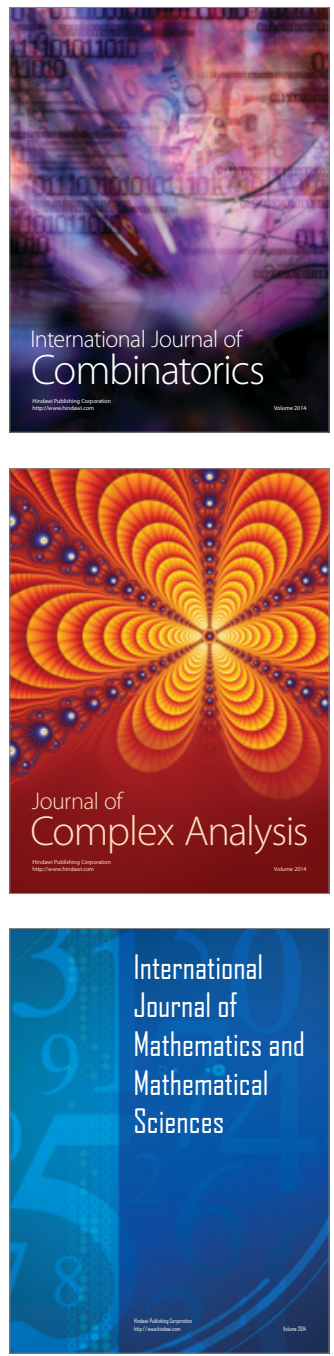
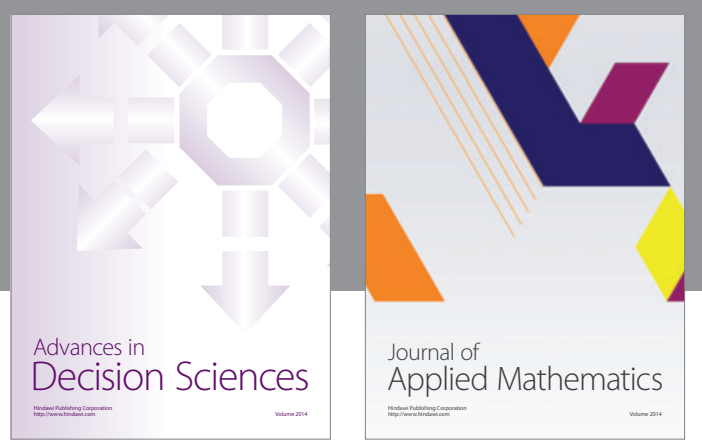

Algebra

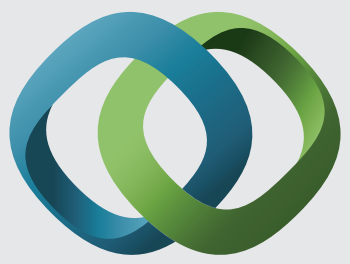

\section{Hindawi}

Submit your manuscripts at

http://www.hindawi.com
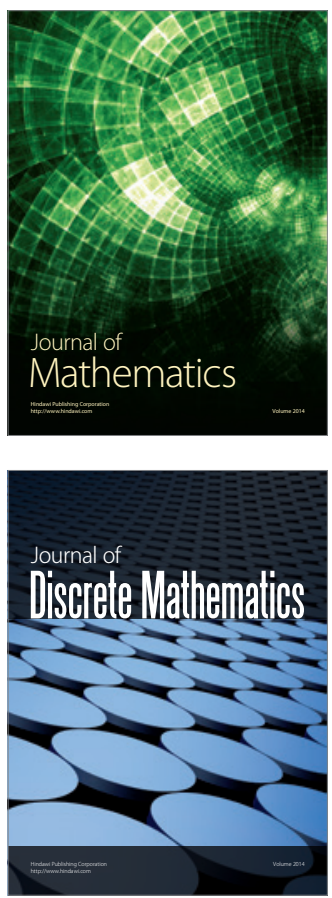

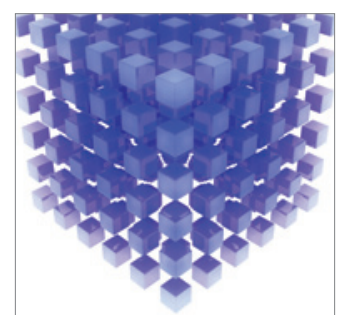

Mathematical Problems in Engineering
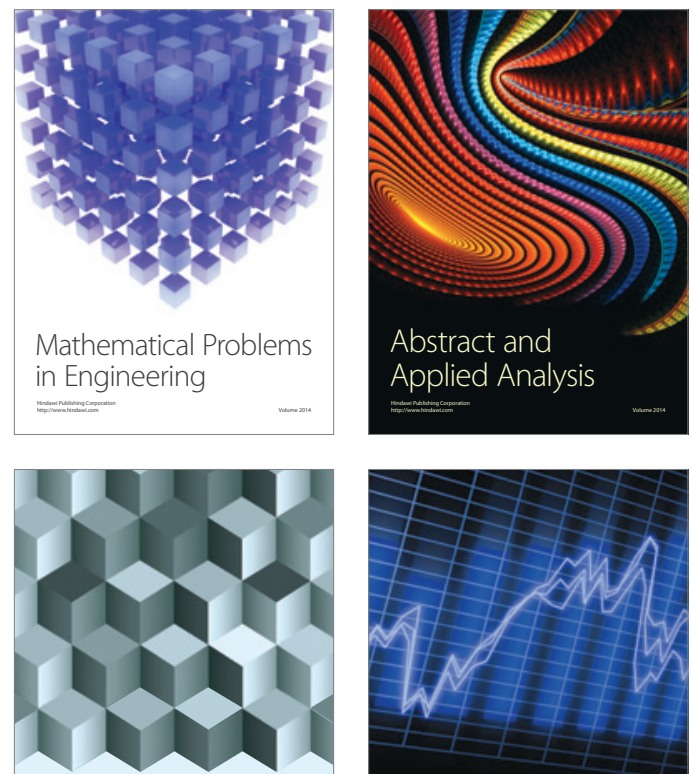

Journal of

Function Spaces

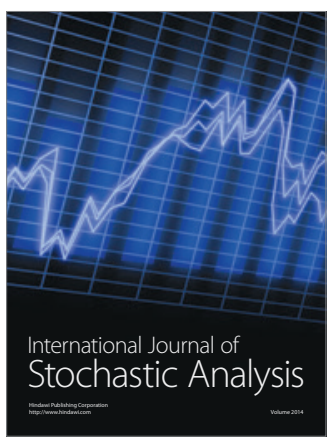

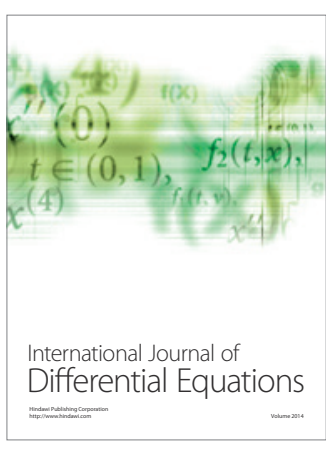
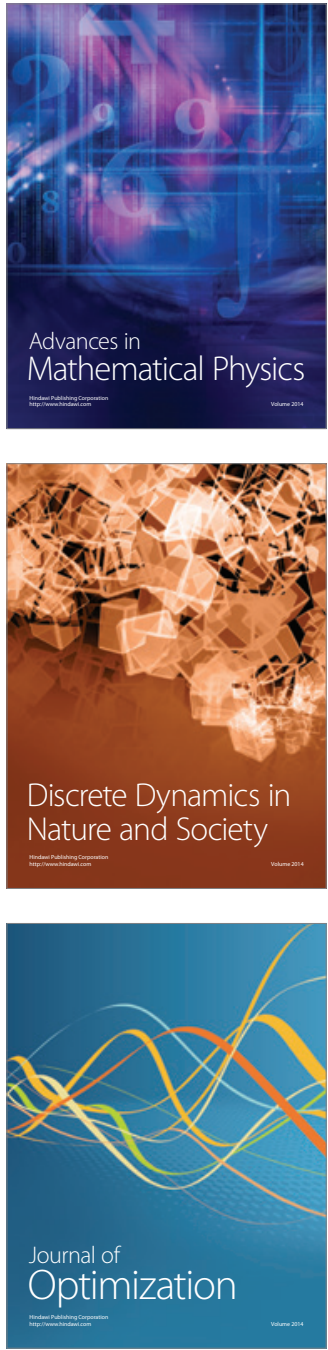